\title{
From surviving to community benefit: A proposed rural health services research agenda
}

\author{
Asa B. Wilson ${ }^{1}$, Bernard J. Kerr' ${ }^{1}$, Nathaniel D. Bastian², Lawrence V. Fulton ${ }^{3}$ \\ 1. Central Michigan University, United States. 2. Penn State University, United States. 3. Texas State University, United \\ States.
}

Correspondence: Asa B. Wilson. Address: 208 Rowe Hall, Central Michigan University, Mount Pleasant, MI 48859, United States. E-mail: wilsolab@cmich.edu

Received: January 11, 2014

Accepted: April 11, 2014

Online Published: April 29, 2014

DOI : 10.5430/jha.v3n5p104

URL: http://dx.doi.org/10.5430/jha.v3n5p104

\section{Abstract}

Background: The research history of rural hospitals from 1980 forward is reviewed. This summary, in turn, becomes a foundation for proposing an updated applied research agenda; one focused on ensuring health services for rural America.

Research history: From 1980 to 1997 rural hospitals closed at a disproportionally higher rate than non-rural facilities. This trend prompted an academic search (Phase I) for the factors associated with the closure-conversion threat to hospitals. The public policy response was the Balanced Budget Act of 1997 and the creation of the Critical Access Hospital (CAH). Once the closure-conversion threat diminished as a result, the research focus (Phase II) shifted from survival to financial performance monitoring, economic efficiency, quality of care, and patient safety of CAHs. Phase II research demonstrates that CAHs can sustain themselves and are not necessarily victims of adverse rural circumstances. Today, CAHs, Rural Health Clinics (RHC) and Federally Qualified Health Centers (FQHC) exist as an established rural health safety net. Also, the 1332 CAHs are considered the hub of health services for rural communities.

Significance: The rural environment remains a changing, challenging arena in which to ensure care for it residents. As such, the expanded Internal Revenue Service (IRS) definition of Community Benefit, specifically the periodic Community Health Needs Assessment (CHNA), provides a template for assessing the rural health safety net's capacity to meet local health needs and improve the health status of its communities. This rubric also balances fiscal stewardship with positive health service outcomes. It is argued that the CHNA expansion of Community Benefit is an ideal research template and performance standard for all rural hospitals. It enables one to offer researched answers to the enduring question, "What is the best way to ensure health services for rural America?”

\section{Key words}

Rural healthcare, Rural hospitals, Critical access hospitals, Community benefit

\section{I ntroduction}

A defined research agenda is an essential framework within which to conduct purposeful, applied research ${ }^{[1,2]}$. Such a conceptual scaffolding guides research producing results capable of augmenting decision-support needs of policy makers and healthcare professionals. In support of this reality, the following discussion will propose an updated rural health services research focus. This outcome will be accomplished by reviewing an earlier rural research agenda. These studies 
exist as a reservoir of research questions, operational definitions, methodologies, and findings with considerable value for future activity. This looking forward through history identifies a foundation for future rural health services research.

Further, such research is increasingly important given the challenges of rural life today. For example, Wood's Survival of Rural American defines demographic trends and the attendant agricultural and economic consequences for rural residents and their communities ${ }^{[3]}$. Egan's essay - The Worst Hard Time - portrays the life experiences of survivors of the 1930s dust bowl. Both authors capture the character and resilience of rural residents as well as the natural threats and opportunities ${ }^{[4]}$. It would be difficult to finish these essays without acquiring a realistic view of present day rural America and its escalating stressors. Both authors create a vivid word picture of the social, economic, and demographic matrix rendering rural healthcare delivery an important matter.

Finally, from a health status perspective, rural residents are characterized as a vulnerable population. Also, rural health facilities, for a number of reasons, have been portrayed as at-risk organizations. In the face of these challenges, policy interventions and applied research have attempted to answer the enduring core question, "What is the best way to ensure health services for rural America?"

\section{Background - the rural healthcare safety net}

Specific Acts are earlier answers to this question. The Rural Health Clinic Services Act of 1977 was a response to declining availability of physicians in rural areas and the resulting diminished access to primary care. The Act allowed physician-supervised mid-level practitioners to provide primary care in Rural Health Clinics (RHC). The 1997 Balanced Budget Act (BBA) established state-by-state rural flex plans supporting cost-based reimbursement for a limited service Critical Access Hospital (CAH). Amendments to the Public Health Service Act of 1938 support on-going funding for establishing Federally Qualified Health Centers (FQHC).

A further result of the BBA and creation of the CAH is a well-defined rural segment of the U.S. health system, e.g., the rural health safety net. Today, RHCs, CAHs, FQHCs, and skilled nursing facilities (SNF) are acknowledged to “...play a critical role in the nation's health care delivery system" ${ }^{[5]}$. These entities constitute a healthcare safety net for the country's 61 million rural residences. This sub-system serves 23\% of the U.S. population through 1332 CAHs and 3720 RHCs. More recently, this safety net has been enhanced by an increasing number of FQHCs in rural underserved or areas designated Health Professional Shortage Areas (HPSA). The addition of rural FQHCs creates a safety net that is a continuum of care consisting of CAHs, FQHCs, Emergency Medical Services, SNFs, and RHCs ${ }^{[6]}$. Even though these policies have had a positive impact on rural health care services, a sustaining answer to the core question remains to be achieved.

Today, the Patient Protection and Affordable Care Act (ACA) and its emerging regulations have limited impact on rural health services. Yet, the rural safety net will undoubtedly confront the statute's performance expectations. For example, the Medicare Shared Savings Program and progressive introduction of Accountable Care Organizations (ACO) questions the feasibility of allowing CAHs, RHCs, and FQHCs to form an ACO serving an assigned rural population. Even though final rules render rural entities ineligible to participate as ACOs, the inquiry signals a future expectation that rural healthcare organizations align themselves with the three-part aim of the ACA, e.g., 1) better care for individuals, 2) better health for populations, and 3) lower growth in expenditures.

The emerging public advocacy and regulatory environment within U.S. health services will intensify a focus on improved clinical outcomes, enhanced patient safety and strengthened operating efficiency - all accomplished as costs are contained. In this arena, the core rural health research question remains, yet with the potential for proposing an amended answer. That is, the confluence of prior rural health research and ACA performance expectations provide an opportunity for defining a future rural research agenda. 


\section{Rural health services research}

Heretofore, parties conducting research on rural health care have had difficulty finding a stable foundation upon which to build. Thus, a literature exists that has occurred in two distinct phases based on two differing views of rural environments and organizations, especially hospitals. The initial phase started in the late 1970s and ended with the 1997 BBA. Phase I was prompted by the alarming closure rate of rural hospitals and a desire to isolate closure-conversion risk factors. These studies focused on external threats confronting rural facilities; characteristics presumed to increase the closure-conversion threat.

By contrast, Phase II began in 1998 and continues as a result of progressive implementation of the BBA. This phase was prompted by: 1) a reduction in the rural hospital closure threat, 2) creation of the CAH, 3) an expanding role of RHCs, 4) an amended CAH reimbursement policy, and 5) an emphasis on facility performance. Research since 2000 has focused on performance aspects of CAHs using fiscal benchmarks, quality of care outcomes, patient safety monitors, and productive efficiency assessments. In spite of focus differences, Phase I and Phase II research pursued an answer to the question of a best approach to providing sustainable rural health services.

\subsection{Phase I: survival emphasis - the closure/ conversion threat}

Between 1979 and 1990, rural hospitals closed at a rate significantly higher than closure rates for urban hospitals. Of this total, 63 percent of closures were rural hospitals. By report, 330 rural hospitals closed presumably because "rural hospitals have been more seriously affected by changes in the environments and financing of health care than any other sector of the healthcare field" ${ }^{[7]}$. The compelling loss of rural hospitals during this time drove studies focused on the challenges of rural health administration, the inherent environmental threats to rural organizations, and the looming specter of closure or conversion.

The list of external threats is often stated as: 1) scarce resources, 2) adverse public policy and legislation, 3) unequal distribution of providers, 4) limited access to capital for technology and building, 5) prospective reimbursement, 6) essential personnel shortages, 7) population out migration, 8) increased dependence upon Medicare, 9) low patient volumes, 10) inadequate information technology, 11) a shift from primary care to specialty services, 12) demographic changes, 13) declining revenues against increasing operating expenses, and 14) unrealistic local economic development expectations. Overall, rural health facilities are viewed as victims of: 1) adverse trends in the total U.S. health system as well as 2) challenges arising from characteristics unique to rural environments ${ }^{[8]}$.

Until the BBA, rural hospitals were considered victims of their rural circumstances, e.g., "For small hospitals, dealing with the changing health care landscape while remaining financially viable and providing adequate health care services to their communities is a formidable challenge" ${ }^{\text {[9] }}$. This outlook results also from a belief that the transition from retrospective to prospective payment was unfair to small and rural facilities ${ }^{[10]}$. The closure rate was considered an example of social Darwinism as hospitals adjusted poorly to the adverse impact of prospective payment. Thus, the rural hospital-as-victim metaphor was reinforced and sustained the search for external factors explanatory of facility closure.

One study addressed this issue by defining the structural determinants of hospital closure. This conceptual model is based on the assumptions of an organization's life cycle and the hospital as an open system. As an open system, the rural hospital is “...vulnerable to uncontrolled, often unpredictable environmental influences” ${ }^{[11]}$. Even though this study attempted to define both internal and external factors associated with hospital closure, it concluded that "these findings suggest that there are indeed forces beyond the control of hospital management that led to eventual failure". Since rural hospitals were victims of untenable circumstances, the closure-conversion risk was considered an unavoidable administrative challenge.

Other Phase I studies focused on the impact of hospital closure on rural communities. Since the hospital is victimized by external forces, the community is a collateral-damage victim as defined by: 1) reduced access to care, and 2) adverse economic consequences. However, in spite of these arguments, research has not confirmed the expected: 1) limited access to care, 2) lowered health status of community residents, and 3) long-lasting adverse impact on community economics. 
The Phase I research question was "What are the factors predictive of hospital closure or conversion?” On this side of the BBA, it is concluded that Phase I research was unable to identify factors predictive of and/or associated with closure or conversion. Also, prior studies used a wide array of dependent and independent variables. Equally problematic is the differing definitions of rural hospital that were used from study to study. Finally, the Phase I agenda is understood as an argument that the way to ensure rural health services is to protect the rural hospital by minimizing the closure-conversion threat.

\subsection{Phase II : from victim to performer}

Phase II begins with the BBA and the progressive conversion of eligible rural hospitals to CAH status. An important feature of CAH conversion was a transition from prospective payment to cost-based reimbursement. A CAH now receives $101 \%$ of allowable costs for care delivered to Medicare and Medicaid beneficiaries. In addition, evidence indicates that conversion to $\mathrm{CAH}$ status reduced the closure/conversion threat for these facilities. Attenuation of the closure-conversion threat is also the foundation for the Phase II emphasis on CAH and RHC performance. Also, the CAH became a frequently used operational definition of rural hospital in subsequent studies. Thus, the Phase II answer to ensuring rural health services is to identify factors that strengthen the performance of CAHs and RHCs. Those factors have been addressed as follows:

\subsubsection{Financial performance}

Early Phase II studies considered the financial performance of CAHs. Research attention was devoted to: 1) establishing fiscal monitors derived from the Medicare Cost Report, 2) monitoring and reporting financial performance according to these benchmarks, and 3) comparing fiscal performance among CAH peer groups. Subsequent research also confirmed that conversion to CAH status and the accompanying shift to cost-based reimbursement led to improved fiscal performance ${ }^{[12-14]}$. For example, a sample of 89 Iowa CAH hospitals over an 8-year post-conversion period showed improved operating revenues, reduced expenses, and positive operating margins ${ }^{[15]}$.

The value of using standard fiscal monitors characterizes the Phase II shift from the facility-as-victim view to an emphasis on management control of organizational adaptability. A hallmark of Phase II research is its emphasis on organizational performance and administrative actions to overcome routine rural challenges. In Phase II, the original rural challenges are not minimized. Rather, they are viewed as administrative opportunities for performance improvement, especially financial ${ }^{[16]}$.

\subsubsection{Frontier efficiency studies}

In 1957, the stage was set for an economics research interest in organizational efficiency. Here, productive efficiency is defined as the ability of an organization to produce outputs with limited resources, i.e., inputs. Productive efficiency of an organization can be increased to a point of perfect efficiency by increasing its level of outputs using the same level of inputs, i.e., "When one talks about the efficiency of a firm one usually means its success in producing as large as possible an output from a given set of inputs” ${ }^{[17]}$.

Since then, an operations research/management science (OR/MS) tool, Data Envelopment Analysis (DEA), was developed as a mathematical programming application to assess the technical efficiency of decision making units (DMU) or organizations ${ }^{[18]}$. DEA is non-parametric, deterministic non-linear programming technique which is used to define the relative efficiency of each decision-making unit in a sample of comparable DMUs. DEA assumes that input and output measures are similar for each DMU in the sample of units.

DEA defines efficiency as the maximized ratio of weighted outputs to weighted inputs subject to the constraint that the ratio for each unit is equal to or less than 1. A DMU within a data set of DMUs having an efficiency ratio of less than 1 is considered inefficient. Decision making units in the same sample with an efficiency ratio of 1 are deemed relatively efficient. DEA efficiency ratios, in turn, allow the investigator to develop an efficiency frontier or data envelope based on the identification of the optimally performing units in the data set. 
These optimally performing units define and lie on the efficiency frontier; a benchmark from which the performance of all other units in the set are compared. Also, the differences between the performance of inefficient entities and those defining the efficiency frontier ("slacks") allow for an analysis of the "cause" of these differences; findings that may identify opportunities for improving the performance of inefficient units.

When DEA is applied to hospitals or clinics performance, an array of input and output variables have been employed. The table summarizes some of the measures used in prior DEA studies using hospitals or clinics.

Table. Summary of input and output variable used in prior DEA studies

\begin{tabular}{ll}
\hline Inputs & Outputs \\
\hline Number of beds & Total outpatient visits \\
Number of physicians & Number of physicians \\
Total non-provider FTEs & Number of RHC visits \\
Total operating expenses & Total patient revenue \\
Average hourly wage rate & Total ER visits \\
FTE nursing hours & Total births \\
Total square feet & Total outpatient surgeries \\
Dollar value of net plant & \\
\hline
\end{tabular}

Though a large inventory of efficiency research on health organizations exists, only a few studies have applied efficiency techniques to rural health facilities. Prior to the BBA, a case-control study was conducted in which closed rural hospitals were matched with comparable sustaining facilities during the 1988 study period ${ }^{[19]}$. This exploratory DEA study assessed whether or not closed hospitals posted technical efficiency differences in comparison to those remaining open. Since no technical efficiency differences were identified between closed and sustaining facilities, it was argued that declining demand for inpatient services was a causative factor in the closure-continuing status differences between the two groups, not inefficiency.

The financial-performance-evaluation template fostered a research interest in operations research applications to technical, cost, and scale efficiency of CAHs and RHC ${ }^{[20]}$. A further efficiency study used DEA methodology to assess the productive efficiency of RHCs in five Midwestern states. From a sample of 163 RHCs, it was determined that 29 percent were deemed DEA efficient. The remaining 71 percent were inefficient having clear opportunities for improvement ${ }^{\text {[21] }}$. Also, the performance of 3,565 RHCs was evaluated during a two-year period. The study's efficiency and macro effectiveness trend results identified future research needed to identify tactics for enhancing RHC performance and ensuring quality outcomes ${ }^{[22]}$.

Further, DEA methodology using CAH financial indicators allows for a differentiation among CAHs on the basis of technical efficiency. The ability to differentiate allows one to use fiscal monitors as benchmarks for tracking performance improvement among CAHs. Also, efficiency research helps shifts the victim dialogue to a focus on how a rural facility uses its resources to generate outputs, i.e., perform. Efficiency studies also identify management control tactics that support continuous performance outcomes. Yet, Phase II frontier studies find that a majority of CAHs and RHCs are inefficient ${ }^{[23-27]}$. However, future research is needed to define links between a single efficiency score and key performance aspects of rural facilities, especially CAHs, RHCs and FQHCs.

\subsubsection{Quality and patient safety monitoring}

Once Phase II studies established that CAHs can sustain themselves financially and that rural health facilities are productively inefficient, questions about quality of care and patient safety were addressed. Transition to these topics occurred in two steps. A research concern for the quality of care delivered in CAHs occurred first. The patient safety environment in rural hospitals, especially CAHs, became a subsequent focus. 


\subsubsection{Quality}

Quality of care has received the bulk of attention starting in $1999^{[28]}$ with a concern for the challenges of rural quality of care, appropriate assessment tools, and the need to clarify a primary quality-of-care objective ${ }^{[29]}$. It was argued that rural facilities should demonstrate an ability to provide care at a level of quality comparable to urban organizations. Since then, the research question has focused on how best to define, measure ${ }^{[29,30]}$, compare ${ }^{[31,32]}$, and report quality-of-care outcomes ${ }^{[14]}$ in rural facilities, especially CAHs.

A watershed publication assessed quality of care delivered in $\mathrm{CAHs}^{[33]}$. It contends that ensuring the survival of CAHs creates an obligation to confirm that high-quality care is delivered by these facilities. Yet, the study reports that CAHs, when compared to non-CAHs, perform poorly as evidenced by: 1) fewer clinical resources, 2) limited progress with establishing EHR, 3) lower Healthcare Quality Alliance (HQA) measures for acute myocardial infarction (AMI), congestive health failure (CHF), and pneumonia admissions, and 4) lesser availability of technical resources. A subsequent study reports a comparatively higher mortality rate among Medicare beneficiaries admitted to CAHs than those admitted to non-CAHs for the same three conditions ${ }^{[34]}$. Additional studies have raised concerns over the relevance of quality measures for CAHs and outpatient services ${ }^{[29]}$.

\subsubsection{Patient safety}

Patient safety emerged as a latter concern over determining what patient safety standards are relevant for rural health facilities and what established national approaches are appropriate for such entities ${ }^{[35,36]}$. These studies accomplished two goals. They identified key patient safety areas and specified patient safety operating priorities for rural hospitals. Follow-up studies report improved patient safety performance following conversion to CAH status ${ }^{[37]}$ and enhanced patient safety activity as a result of implementing patient safety systems in rural hospitals ${ }^{\text {[38] }}$. Additional attention has been given to the challenge of and strategies for establishing patient safety systems within rural facilities ${ }^{[39,40]}$. Here, the assurance of a safe environment is identified as a collective governance-administrative responsibility; one supported by applying established patient safety measures and employing available information technology ${ }^{[39]}$. In addition, there are continued efforts to compare patient safety outcomes between urban and rural hospitals ${ }^{[41,42]}$.

\subsubsection{Remaining phase I and II research needs}

The Phase I emphasis on risk of closure or conversion provided a group of studies to which a meta-analytic technique should be applied. It is necessary to review these studies for the purpose of identifying risk factors. The rural environment is dynamic and continues to challenge its health service organizations. So much so, that a retrospective review of earlier closure-conversion studies will help clarify potential future risks. An essential corollary research question is, "What is the population floor or threshold below which a CAH-RHC system cannot be sustained?” Another unaddressed question is, "At what point does a rural FQHC or RHC become a cost-effective approach to meeting the primary care needs of a rural community?” These needed follow-up studies shift the closure-conversion concern out of the original threat rubric into a positive emphasis on the health needs of a defined area.

Phase II research demonstrates that CAHs can sustain themselves. Phase II studies on CAH financial monitors, fiscal performance, productive efficiency, quality of care, and patient safety have created opportunities for needed future studies. An important unaddressed question is, "How are DEA frontier results related to fiscal, quality, and safety performance of CAHs and RHCs?” The collection of Phase II studies exist as standalone efforts that need to be linked to other aspects of performance. That is, what does a technical efficiency measure reflect regarding the other aspects of an organization's performance? Or, "How can these earlier finding be used to further identify ways by which DEA inefficient CAHs and RHCs can become less inefficient?”

The collective impact of this additional research fosters a transition to an essential rural health service concern. Rural healthcare research and delivery stand at a perfect transition threshold. It has been argued that "access and quality of health care services should be measured via their impact on the health outcomes of the population, not the consumption of health 
care services per se” ${ }^{[26]}$. The point has now been reached at which a best approach to ensuring rural health services is to focus on the extent to which the rural safety net's priority is continuously improving the health status of it defined community.

\subsubsection{CAH affiliation and acquisition considerations}

Though the rural hospital closure rate has abated since 1998, these facilities continued to pursue survival tactics. For example, many CAHs contracted with hospital management companies or have been acquired by non-profit health systems. This latter approach is consistent 1 ) the rate of mergers occurring among health systems and 2) the rural intent to further reduce the presumed threats of a stand-alone status.

While not directly stated, the intent of the BBA and the resultant Medicare Rural Flexibility Program was to minimize the original closure-conversion threat by bulwarking the stand-alone capabilities of rural hospitals, especially the growing number of those converting to CAH status. However, the rate of rural hospitals affiliating with or being acquired by health systems has changed the landscape of rural hospitals. These amendments pose policy, administrative, and service issues for these facilities and their communities.

For example, affiliations and acquisitions have in effect created three CAH peer groups. One group continues to operate as stand-alone facilities. A second group has affiliated with hospital management companies thereby adding management fees and purchase service expenses to its operating costs. A third group has been acquired by a large, near-by health system and absorbs allocated costs from the system. All three CAH groups continue to benefit from cost-based reimbursement for services provided to Medicare and Medicaid beneficiaries and from increased allowable costs. This latter reality means that a public reimbursement policy now benefits the larger health system rather than the CAH exclusively.

A compelling research question is "What is the post affiliation-acquisition impact on the fiscal performance these groups of CAHs?” Of equal importance is the need to assess the comparative productive efficiency, quality reporting, and safety status of these CAH groups. This research will enable policy makes to address whether or not to allow affiliated and/or acquired CAHs to continue benefiting from cost-based reimbursement. It could be argued that CAHs should be required to revert to prospective payment, especially since acquired CAHs are an outreach function or external department of the acquiring health system.

Also, acquisition creates an illusion of reduced risk for the CAH. While not researched to date, there is every reason to argue that the acquiring health system will continuously enhance its specialty care volume by referrals generated from its visiting sub-specialists. A predictable "side effect" of this patient out-flow will be a narrowing of the CAH's scope of service and a decline in inpatient-outpatient volume. As this transition gains momentum, the corporations could have an incentive to convert acquired CAHs to a RHC, FQHC, or urgent care clinic.

Today, an essential research need is a before-and-after acquisition assessment of volume levels and scope of services provided by CAHs. The question is whether or not this group of CAHs is maintaining a mix of primary care services that justifies its continued CAH status and fulfills its community benefit obligation. The answer will help provide policy guidance on a best approach to ensuring care within the local community given that volume and dollars are moving to the acquiring system. Note also that this situation supports the following emphasis on community benefit as a research opportunity and rural health service responsibility.

\section{From surviving to providing community benefit}

For now, the CAH remains the hub of a rural community's health services. Phase II has demonstrated that 1332 CAHs are capable, under current conditions, of sustaining themselves. It has been shown also that there are compelling opportunities for CAHs to improve clinical outcomes, enhance patient safety environments, and reduce productive inefficiencies. Even 
though most RHCs are deemed inefficient, their numbers have increased throughout rural America. Finally, the rural continuum of care has been enhanced by expanding FQHC-hospital collaborations ${ }^{[7]}$. In spite of the apparent stability of the rural health safety net, an excellent research and policy opportunity presents itself.

\subsection{The community benefit template}

Such an opportunity exists under the umbrella of community benefit as defined by the U.S. Internal Revenue Service (IRS). From 1969, a hospital's tax exempt status has been contingent upon providing specified benefits to its community. In 2008, the IRS required formal reporting (Schedule H, Form 990) of the dollar value of designated activities, e.g., 1) charity care, 2) unreimbursed costs of means tested government programs, 3) subsidized health services, 4) cash and in-kind community contributions, 5) research, 6) community health improvement, and 7) health-professions education. In 2010, the community benefit requirement was expanded to include a Community Health Needs Assessment (CHNA). The CHNA is a tool for demonstrating a facility's commitment to assessing the community's priority health needs and to aligning facility operations with the identified needs.

\subsubsection{CHNA}

The expanded definition of community benefit provides a template for applied research on the performance of rural non-profit hospitals. The ACA and the IRS now require action beyond stating the dollar value of routine community benefit provisions in the form of a periodic CHNA and a follow-up implementation plan. Once completed, the CHNA is to be followed by an annual attestation that the identified health needs of the defined community are being met ${ }^{[43]}$. In turn, the CHNA is a framework for defining a measurable community focus for a rural health safety net facility and its population health needs responsibility. Also, CHNA requirements create an opportunity for the hospital to strengthen the local continuum of care and enhance coordination of care. In doing so, implementation of the CHNA ensures that a community's health service needs are defined as are the optimal resources required to meet these local priorities.

While the expanded community benefit requirements are for charitable hospitals, these standards have applied value for non-charitable rural facilities as well. These IRS requirements provide an inventory of organizational behaviors that are focused on priority health needs, coordination of care, documented health outcomes, community involvement, reporting transparency, and operating efficiencies. As such, these performance expectations are easily incorporated into Medicare's Conditions of Participation (CoP) for all rural hospitals. The expanded community benefit template also enables hospital boards and administrators to quantify the nature and extent of services needed in their respective communities.

\subsubsection{Emerging challenges to a rural community benefit policy}

There are two public policy challenges to such a perspective. First, there is limited commitment to community health needs provisions on the part of U.S. hospitals. In fiscal 2009, not-for-profit hospitals posted an average of $7.5 \%$ of Total operating expenses for community benefit. Of this amount, only $5 \%$ went to community health activities. Further, it is shown that observed wide variations in community benefit expenditures were not accounted for by variables that define: 1) community, 2) institutional, or 3 ) market attributes ${ }^{[44]}$. Since community, institutional, or market characteristics are not drivers of a facility's community benefit expenditure levels, it follows that a hospital's level of community benefit offerings are a matter of facility discretion. Even prior to 2010, a consistent finding is that limited community benefit activities were devoted to enhancing the health status of a hospital's area population.

The ACA has created an expanded expectation about the performance of health facilities. This shift fosters a focus on service outcomes, enhanced health status of populations, measured value of services, and amended reimbursement tactics. In addition, the individual mandate and impending greater demand for access to care create pressure on facilities to perform at higher levels. Revised community benefit requirements transcends the original survival focus and underscores the importance of financial, efficiency, patient safety, and quality-of-care performance for rural hospitals, especially CAHs. 
A second challenge is an argument aimed at rural hospitals in general and CAHs specifically. The Congressional Budget Office (CBO) contends that the CAH program costs Medicare $\$ 2$ billion annually. This amount translates to an average of $\$ 860,000$ per year per CAH because CAHs are reimbursed at $101 \%$ of allowable costs for services provided to Medicare and Medicaid beneficiaries ${ }^{[45]}$. Also, the Office of the Inspector General (OIG) argues that 849 CAHs would not qualify for this designation today if the original location and distance criteria were enforced ${ }^{[46]}$.

The CBO and OIG reports challenge the value of the CAH program and recommend interventions unfavorable to rural hospitals. The CBO proposes eliminating the CAH, Medicare Dependent Hospital (MDH), and Sole Community Hospital (SCH) programs; a tactic that presumes to reduce federal Medicare expenditures by $\$ 23$ billion over a four-year period. Projected reductions are the result of discontinuing higher Medicare payments to rural hospitals so classified. The OIG recommends reducing Medicare reimbursement to CAHs from 101\% to $100 \%$ of allowable costs. Also, enforcing and amending the distance requirement for CAH designation presumes to save Medicare $\$ 40$ million by eliminating 70 CAHs that are less than 10 miles from the nearest hospital. Changing the distance requirement to 15 miles would yield a projected \$268 million of Medicare expenditures for CAHs.

\subsubsection{Community benefit research needs}

While implementation of either or both sets of cost-reduction recommendations will have an adverse impact on rural health services ${ }^{[47]}$, the cost-reduction emphasis is poorly timed. They diminish the value of needed policy, administrative, service delivery research opportunities. Rather than arguing about the present-day relevance of the 1997 Medicare CAH program ${ }^{[44,45]}$ by defining the problem as higher than necessary reimbursement, the CHNA requirement, once researched, is a priority policy and administrative decision-support tool.

In response to the overarching core rural health question, "What is a best way to ensure health services for rural America?" it is argued that the historical rural hospital concern for survival should be replaced by a priority focus on the improved health status of service area populations. In support of this appeal the following research information is needed:

- Community Benefit Baseline Results. What are the baseline community benefit provisions delivered from 2010 forward by tax-exempt rural hospitals, e.g., CAHs, MDHs, and SCHs?

- Community Benefit Provisions by Non-charitable Rural Hospitals. In what ways do non-charitable rural entities voluntarily provided community benefits, especially those activities devoted to health status enhancement?

- CHNA Review. What CHNA methodologies have be employed to date by rural tax-exempt facilities? What are the healthcare priority needs identified by CHNAs conducted to date?

- Alternative Organizational Configuration. Instead of sustaining a CAH, could a community's health service needs be met by an alternative configuration such as a FQHC or a RHC?

\section{Summary}

Today, CAHs, FQHCs, and RHCs are established, the sustaining service units of the rural healthcare infrastructure. Also, Phase I research remains a pool of studies available for further analysis leading to needed research answers regarding performance improvement and sustainability of rural health facilities. Phase II research provides methods, measures, and, results regarding CAH and RHC performance. Needed Phase II follow-up research will further strengthen an understanding of performance improvement opportunities for these organizations.

In addition, the expanded definition of community benefit and the population health focus of the ACA create a research climate aligned with U.S. health reform and rural healthcare service needs. We have reached the point at which the rural healthcare safety net can expand its mission beyond surviving by demonstrating a commitment to improving the health 
status of its populations. Such a pursuit will focus the rural service mission and will align rural health care with the three-part aim of the ACA, e.g., 1) better care for individuals, 2) better health for populations, and 3) lower growth in expenditures.

\section{References}

[1] Khun, TS. The structure of scientific revolutions (3rd Ed.), Chicago, IL, University of Chicago Press, 1996. PMid: 8671238. http://dx.doi.org/10.7208/chicago/9780226458106.001.0001

[2] Moscovice, I, Stensland J. Rural hospitals: Trends, challenges, and a future research and policy analysis agenda. J Rural Health. 2002; 18: 197-210. PMid: 12061514. http://dx.doi.org/10.1111/j.1748-0361.2002.tb00931.x

[3] Wood RE. Survival of rural America: Small victories and bitter harvests. Lawrence, KS. University Press of Kansas, 2008.

[4] Egan T. The worst hard time: The untold story of those who survived the great American dust bowl. New York, NY. Houghton Mifflin Co. 2006.

[5] Rosenblatt RA. Quality of care in the rural context: A proposed research agenda. J Rural Health. 2002; 18: 176-185. PMid: 12061512. http://dx.doi.org/10.1111/j.1748-0361.2002.tb00929.x

[6] Samuels, ME, Xirasagar, S, Elder, KT, Probst, JC. Enhancing the care continuum in rural areas: Survey of community health center-rural hospital collaborations. J Rural Health. 2008; 24: 24-31. PMid: 18257867. http://dx.doi.org/10.1111/j.1748-0361.2008.00133.x

[7] Chan, B, Feldman, R, Manning WG. The effects of group size and group economic factors on collaboration: A study of the financial performance of rural hospitals in consortia. Health Serv Res. 1999; 34: 9-31. PMid: 10201850.

[8] Hatten, J, Connerton RE. Urban and rural hospitals: How do they differ? Health Care Financ Rev. 1986; 8: 77-85. PMid: 10312014.

[9] Blanchfield, BB, Franco, S J, Mohr PE. Critical access hospitals: How many rural hospitals will meet the requirements? J Rural Health. 2000; 16: 119-128. PMid: 10981363. http://dx.doi.org/10.1111/j.1748-0361.2000.tb00445.x

[10] Gianfrancesco, F. D. The fairness of the PPS reimbursement methodology. Health Serv Res. 1990; 25: 1-23. PMid: 2109738.

[11] Longo, DR, Chase, GA. Structural determinants of rural hospital closure. Med Care. 1984; 22: 388-402. PMid: 6717119. http://dx.doi.org/10.1097/00005650-198405000-00003

[12] Pink, GH, Holmes, GM, Slifkin, RT, Thompson RE. Developing financial benchmarks for critical access hospitals. Health Care Financ Rev. 2009; 30: 55-69. PMid: 19544935.

[13] Pink, GH, Holmes, GM, D’Alpe, C, Strunk, LA, McGee, P, Slifkin RT. Financial indicators for critical access hospitals. J Rural Health. 2006; 23: 1004-1048.

[14] Pink, GH, Slifkin, RT, Coburn, AF, Gale, JA. Comparative performance data for critical access hospitals. J Rural Health. 20: 374-382. PMid: 15551855. http://dx.doi.org/10.1111/j.1748-0361.2004.tb00052.x

[15] Li, P, Schneider, JE, Ward, MM. Converting to critical access status: How does it affect rural hospitals’ performance? Inq. 2009; 46: 46-57. http://dx.doi.org/10.5034/inquiryjrnl_46.01.46

[16] Holmes, GM, Pink, GH. Adoption and perceived effectiveness of financial improvement strategies in critical access hospitals. J Rural Health. 2012; 28: 92-100. PMid: 22236319. http://dx.doi.org/10.1111/j.1748-0361.2011.00368.x

[17] Farrell, MJ. The measurement of productive efficiency of production. J Royal Stat Soc, Series A. 1957; 123: $253-281$. http://dx.doi.org/10.2307/2343100

[18] Charnes, A, Cooper, WW, Rhodes E. Measuring the efficiency of decision making units. Euro J Oper Res. 1978 ; 2 : 429-444. http://dx.doi.org/10.1016/0377-2217(78)90138-8

[19] Ozcan, YA, Lynch, J. Rural hospital closures: An inquiry into efficiency. Adv Health Econ Health Serv Res. 1992; 13: $205-224$. PMid: 10129444.

[20] Hollingsworth B. The measurement of efficiency and productivity of health care delivery. Health Econ. 2008; 17: 1107-1128. PMid: 18702091. http://dx.doi.org/10.1002/hec.1391

[21] Sinay T. Productive efficiency of rural health clinics: The Midwest experience. J Rural Health. 2001; 17: 239-250. PMid: 11765888. http://dx.doi.org/10.1111/j.1748-0361.2001.tb00961.x

[22] Ortiz, J Wan TH. Performance of rural health clinics: An examination of efficiency and Medicare beneficiary outcomes. J Rural Remote Health. 2012; 40: 1-11.

[23] Probst, JC, Laditka, JN, Laditka, SB. Association between community health center and rural health clinic presence and county-level hospitalization rates for ambulatory care sensitive conditions: An analysis across eight US states. BMC Health Serv Res. 2009; 1-11.

[24] Butler, TW, Li L. The utility of returns to scale in DEA programming: An analysis of Michigan rural hospitals. Eur J Oper Res. 2005; 161: 469-477. http://dx.doi.org/10.1016/j.ejor.2003.09.019 
[25] Harrison, JP, Ogniewski, R, Hoescher S. The improving efficiency of Critical Access Hospitals, Health Care Manager. 2009; 28: 55-69. PMid: 19668061. http://dx.doi.org/10.1097/HCM.0b013e3181b3e968

[26] Rosko, MD, Mutter RL. Inefficiency differences between critical access hospitals and prospectively paid rural hospitals. J Health Politics Law. 2010; 35: 95-126. PMid: 20159848. http://dx.doi.org/10.1215/03616878-2009-042

[27] Wilson, AB, Kerr, BJ, Fulton, L, Bastian N. Financial performance monitoring of the technical efficiency of critical access hospital: A data envelopment analysis and logistic regression modeling approach. J Healthc Manag. 2012; 57: 200-212. PMid: 22724377.

[28] Capalbo, SM., Heggem CN. Valuing rural health: Issues of access and quality. Am J Agric Econ. 1999 August: 674-679. http://dx.doi.org/10.2307/1244033

[29] Moscovice, I, Rosenblatt R. Quality of care challenges for rural health. J Rural Health. 2000; 16: 168-176. PMid: 10981369. http://dx.doi.org/10.1111/j.1748-0361.2000.tb00451.x

[30] Moscovice, R, Wholey, DR, Klinger, J, Knott A. Measuring rural hospital quality. J Rural Health. 2004; 20: 383-393. PMid: 15551856. http://dx.doi.org/10.1111/j.1748-0361.2004.tb00053.x

[31] Casey, MM, Prased, S, Klinger, J, Moscovice I. Are the CMS hospital outpatient quality measures relevant for rural hospitals? J Rural Health. 2012; 2: 248-259. PMid: 22757949. http://dx.doi.org/10.1111/j.1748-0361.2012.00406.x

[32] Lutfiyya, MN, Bhat, DK, Gandhi, SR, Nguyen, C, Weidenbacher-Hoper, VL, Lipsky M. S. A comparison of quality of care indicators in urban acute care hospital and rural critical access hospitals in the United States. Int J Qual Healthc. 2007; 19: 141-149. PMid: 17442745. http://dx.doi.org/10.1093/intqhc/mzm010

[33] Joynt, KE, Harris, Y, Orav, EJ, Jha AK. Quality of care and patient outcomes in critical access rural hospitals. JAMA. 2011; 306: 4552.

[34] Joynt, KE, Orav, EJ, Jha AK. Mortality rates of Medicare beneficiaries admitted to critical access and non-critical access hospitals, 2002-2010. JAMA. 2013; 309: 1379-1387. PMid: 23549583. http://dx.doi.org/10.1001/jama.2013.2366

[35] Coburn, AF, Wakefield, M, Casey, M, Moscovice, I, Payne, S, Loux S. Assuring rural hospital patient safety: What should be the priorities? J Rural Health. 2004; 20: 314-326. PMid: 15551848. http://dx.doi.org/10.1111/j.1748-0361.2004.tb00045.x

[36] Casey, MM, Wakefield, M, Coburn, AF, Moscovice, IS, Loux S. Prioritizing patient safety interventions in small and rural hospitals. J Qual Patient Saf. 2006; 32: 693-702.

[37] Li, P, Schneider, JE, Ward MM. Effect of Critical Access Hospital conversion on patient safety. Health Serv Resh. 2007; 42: 2089-2107. PMid: 17995554. http://dx.doi.org/10.1111/j.1475-6773.2007.00731.x

[38] Longo, DR, Hewett, JE, Ce, B, Schubert S. Rural hospital patient safety systems implementation in two states. J Rural Health. 2007; 23: 189-197. PMid: 17565518. http://dx.doi.org/10.1111/j.1748-0361.2007.00090.x

[39] Westfall, JM, Fernald, DH, Staton, EW, NanVorst, R, West, D, Pace WD. Applied strategies for improving patient safety: A comprehensive process and frontier communities, J Rural Remote Health. 2004; 20: 355-362. http://dx.doi.org/10.1111/j.1748-0361.2004.tb00049.x

[40] Wholey, D, Moscovice, I., Hietpas, T, Holtzman J. The environmental context of patient safety and medical errors, J Rural Health. 2004; 20: 304-313. PMid: 15551847. http://dx.doi.org/10.1111/j.1748-0361.2004.tb00044.x

[41] Klinger, J, Moscovice, I, Tupper, J, Ches, AC, Wakefield M. Implementing patient safety initiatives in rural hospitals, J Rural Health. 2009; 25: 352-357. PMid: 19780914. http://dx.doi.org/10.1111/j.1748-0361.2009.00243.x

[42] Vartak, S, Ward, MM, Vaughn TE. Patient safety outcome in small urban and rural hospitals. J Rural Health. 2010; 26: 56-66. PMid: 20105269. http://dx.doi.org/10.1111/j.1748-0361.2009.00266.x

[43] Internal Revenue Service US. Community health needs assessments for charitable hospitals. Notice of proposed rulemaking. Fed Regist. 2013; April 5; 78(66): 20523-544.

[44] Young, GJ, Chou, C, Alexander, J, Lee, DL, Raver E. Provision of community benefits by tax-exempt hospitals. NEJM. 2013; 368: 1519-1527. PMid: 23594004. http://dx.doi.org/10.1056/NEJMsa1210239

[45] Reducing the deficit: Spending and revenue options. Washington (DC): The Congress of the United States, Congressional Budget Office; 2011 Mar. 562 p. (CBO publication; no. 4212).

[46] Most critical access hospitals would not meet the location requirements if required to re-enroll in Medicare. Rockville (MD); Department of Health and Human Services (US), Office of Inspector General. 2013 Aug; 34 p. (OIG publication; no. OEI-05-12-00080).

[47] Young, GJ, Chou, C, Alexander, J, Lee, DL, Raver E. Provision of community benefits by tax-exempt hospitals. NEJM. 2013; 368: 1519-1527. PMid: 23594004. http://dx.doi.org/10.1056/NEJMsa1210239

[48] Holmes, GM, Pink, GH, Friedman SA. The financial performance of rural hospitals and implications for elimination of the critical access hospital program. J Rural Health. 2013; 29: 140-190. PMid: 23551644.

http://dx.doi.org/10.1111/j.1748-0361.2012.00425.x 